\title{
Base-Mediated Generation of Ketenimines from Ynamides: [3+2] Annulation with Azaallyl Anions.
}

Agathe C. A. D'Hollander, ${ }^{a}$ Eugénie Romero, ${ }^{a}$ Kamsana Vijayakumar, ${ }^{a}$ Camille Le Houérou, ${ }^{a}$

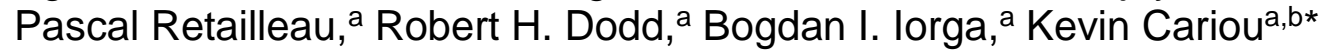

a Université Paris-Saclay, CNRS, Institut de Chimie des Substances Naturelles, LabEx LERMIT, UPR 2301, 91198, Gif-sur-Yvette, France.

b Chimie ParisTech, PSL University, CNRS, Institute of Chemistry for Life and Health Sciences, Laboratory for Inorganic Chemical Biology, 75005 Paris, France.

ABSTRACT: Under basic conditions and heat, ynamides can serve as precursor to ketenimines, whose synthetic potential is often hampered by their difficulty of acces. Herein, we report that they can undergo a [3+2] cycloaddition with 2-azaallyl anions, obtained from benzylimines under the same reaction conditions. This reaction between two highly reactive intermediates, both generated in situ from bench stable starting materials, gives access to various nitrogen-rich heterocycles. The reaction usually proceeds with excellent diastereoselectivity, in favor of the cis adduct. Deuteration experiments and DFT calculation helped rationalize the regio and stereo-selectivity of the process as well as the formation of side-products..

Long before the discovery of penicillin, Staudinger devised a straightforward access to the $\beta$-lactam ring by a [2+2] cycloaddition between a ketene and an imine (Scheme 1a). ${ }^{1}$ This reaction, named the Staudinger synthesis, set the template for accessing this particular heterocycle and inspired a myriad of synthetic variations. ${ }^{2}$ Our group developed an imino-variant of this transformation by using an ynamide $(1 \mathbf{a})^{3-5}$ to generate in situ a highly reactive ketenimine $(2 a)^{6-8}$ which can engage in a [2+2] cycloaddition with a diaryl imine (3a) to give an azetidinimine (Scheme 1b) ${ }^{9,10}$ Exploring this transformation further, we found that when the same reaction conditions were applied to the homologous benzylimine $\mathbf{3 b}$, the formation of the expected azetidinimine was not observed. Instead, 2,5-dihydro-1H-imidazole 6ab was obtained with a $39 \%$ yield (Scheme 1c). We hypothesized that this 5-membered ring arose from a [3+2] cycloaddition between the ketenimine and with semi-stabilized 2-azaallyl lithium $\mathbf{5 b}$, which was also formed in situ under the basic reactions conditions. ${ }^{11,12}$ Overall, reports of 1,3 dipolar cycloaddition with a ketenimine as the dipolarophile remain rather scarce. ${ }^{13-15}$ Moreover, [3+2] cycloadditions with non- or semi-stabilized azallylanions ${ }^{16,17}$ were mostly developed with olefins as the dipolarophiles. ${ }^{18-20}$ This serendipitous discovery thus gave us the opportunity to explore some unprecedented annulation reactions towards nitrogen-rich heterocycles.

To optimize this transformation we decided to react ynamide $1 \mathrm{a}$ with imine $3 \mathrm{c}$ bearing two $p$-chlorobenzene moieties, which would lead to a symmetrical 2-azaallyl anion (Table 1). 


\section{Scheme 1. [2+2] and [3+2] annulations involving ketenes, ketenimines and imines}

a. Staudinger Synthesis

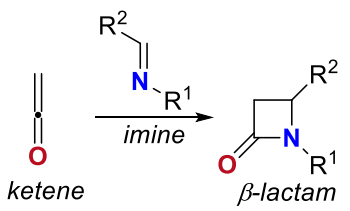

b. Imino-Staudinger with ketenimines

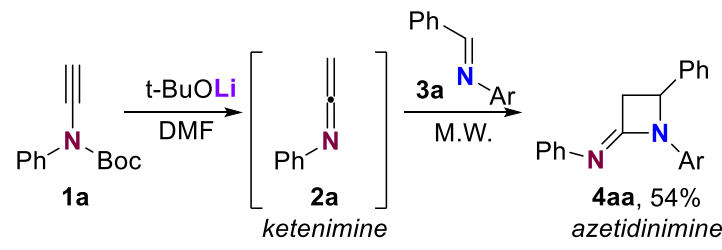

c. $[3+2]$ annulation with ketenimines

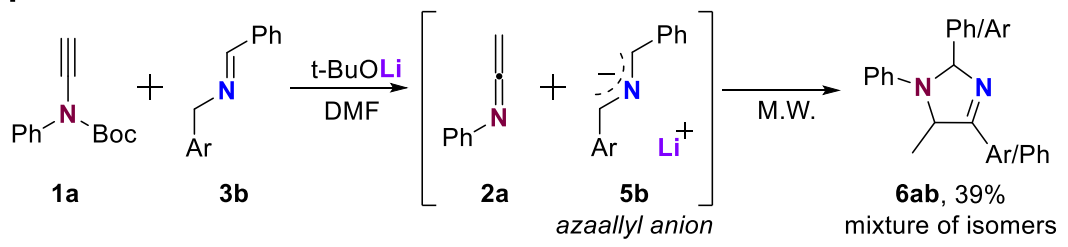

Table 1. Optimization of the reaction conditions ${ }^{a}$
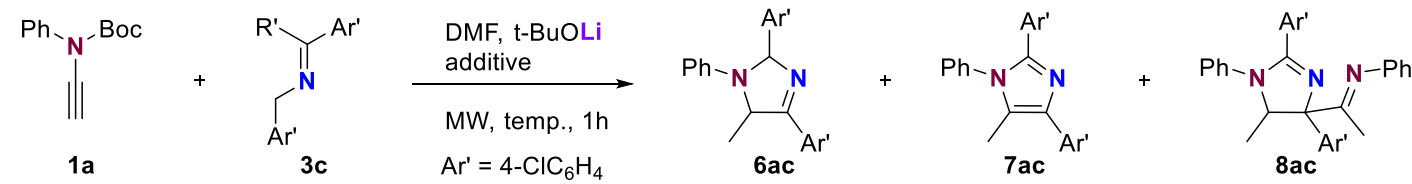

\begin{tabular}{|c|c|c|c|c|c|c|c|c|}
\hline Entry & $\begin{array}{l}\text { equiv. } 1 \mathrm{a} / \\
\text { equiv. } \mathbf{3 c}\end{array}$ & $\begin{array}{l}\text { Base } \\
\text { (equiv.) }\end{array}$ & $\begin{array}{l}\text { Additive } \\
\text { (mol\%) }\end{array}$ & Solvent & Temp. & $\begin{array}{c}\text { Yield 6ac } \\
(\%)^{b}\end{array}$ & $\begin{array}{c}\text { Yield 7ac } \\
(\%)^{b}\end{array}$ & $\begin{array}{c}\text { Yield 8ac } \\
(\%)^{b}\end{array}$ \\
\hline 1 & $2.0 / 1.0$ & $\begin{array}{c}t \text {-BuOLi } \\
(2.0)\end{array}$ & none & DMF (0.5 M) & $100^{\circ} \mathrm{C}$ & $23( \pm 3)$ & $16( \pm 1)$ & $12( \pm 1)$ \\
\hline 2 & $2.0 / 1.0$ & $\begin{array}{l}t \text {-BuOLi } \\
(2.0)\end{array}$ & none & $\mathrm{DMF}(0.2 \mathrm{M})$ & $100^{\circ} \mathrm{C}$ & $45( \pm 2)$ & $7( \pm 2)$ & $12( \pm 1)$ \\
\hline 3 & $2.0 / 1.0$ & $\begin{array}{c}t \text {-BuOLi } \\
(2.0)\end{array}$ & none & THF (0.2 M) & $100^{\circ} \mathrm{C}$ & 0 & 0 & 0 \\
\hline 4 & $2.0 / 1.0$ & $\begin{array}{c}t \text {-BuOLi } \\
(2.0)\end{array}$ & none & DMA (0.2 M) & $100^{\circ} \mathrm{C}$ & $16( \pm 3)$ & $15( \pm 3)$ & $25( \pm 3)$ \\
\hline 5 & $2.0 / 1.0$ & none & none & DMF $(0.2 \mathrm{M})$ & $100^{\circ} \mathrm{C}$ & 0 & 0 & 0 \\
\hline 6 & $2.0 / 1.0$ & $\begin{array}{c}\mathrm{Cs}_{2} \mathrm{CO}_{3} \\
(2.0)\end{array}$ & none & DMF (0.2 M) & $100^{\circ} \mathrm{C}$ & 0 & 0 & 0 \\
\hline 7 & $2.0 / 1.0$ & $\begin{array}{l}\text { DBU } \\
(2.0)\end{array}$ & none & DMF (0.2 M) & $100^{\circ} \mathrm{C}$ & 0 & 0 & 0 \\
\hline $8^{c}$ & $2.0 / 1.0$ & $\begin{array}{c}t \text {-BuOLi } \\
(\mathbf{2 . 7 5 )}\end{array}$ & $\begin{array}{c}\mathrm{Zn}(\mathrm{OAc})_{2} \cdot 2 \mathrm{H} 2 \mathrm{O} \\
(10)\end{array}$ & $\mathrm{DMF}(0.2 \mathrm{M})$ & $100^{\circ} \mathrm{C}$ & $61( \pm 3)$ & $8( \pm 1)$ & $7( \pm 1)$ \\
\hline $9^{c}$ & $2.0 / 1.0$ & $\begin{array}{c}t \text {-BuOLi } \\
(2.75) \\
\end{array}$ & $\mathrm{Cu}(\mathrm{OAc})_{2}(10)$ & DMF (0.2 M) & $100^{\circ} \mathrm{C}$ & $55( \pm 1)$ & $6( \pm 1)$ & $2( \pm 2)$ \\
\hline $10^{c}$ & $2.0 / 1.0$ & $\begin{array}{c}t \text {-BuOLi } \\
(\text { (3.3) }\end{array}$ & $\mathrm{Zn}(\mathrm{OTf})_{2}(10)$ & DMF (0.2 M) & $100^{\circ} \mathrm{C}$ & $63( \pm 4)$ & $(8 \pm 1)$ & $8( \pm 2)$ \\
\hline $11^{\mathrm{c}}$ & $2.0 / 1.0$ & $\begin{array}{c}t \text {-BuOLi } \\
(2.75)\end{array}$ & $\begin{array}{c}\mathrm{Zn}(\mathrm{OAc})_{2} \cdot 2 \mathrm{H} 2 \mathrm{O} \\
(10)\end{array}$ & DMF (0.2 M) & $80^{\circ} \mathrm{C}$ & $60( \pm 4)$ & $7( \pm 2)$ & $7( \pm 2)$ \\
\hline $12^{\mathrm{c}}$ & $1.5 / 1.0$ & $\begin{array}{c}t \text {-BuOLi } \\
(2.75)\end{array}$ & $\begin{array}{c}\mathrm{Zn}(\mathrm{OAc})_{2} \cdot 2 \mathrm{H} 2 \mathrm{O} \\
(10)\end{array}$ & DMF (0.2 M) & $80^{\circ} \mathrm{C}$ & 50 & Traces & Traces \\
\hline $13^{c}$ & $1.5 / 1.0$ & $\begin{array}{l}t \text {-BuOLi } \\
(4.4)\end{array}$ & $\begin{array}{c}\mathrm{Zn}(\mathrm{OAc})_{2} \cdot 2 \mathrm{H} 2 \mathrm{O} \\
(10)\end{array}$ & DMF (0.2 M) & $80^{\circ} \mathrm{C}$ & $62( \pm 1)$ & Traces & Traces \\
\hline
\end{tabular}

${ }^{a}$ All reactions were carried out with $0.15 \mathrm{mmol}$ of $\mathbf{3 c}$, and in a microwave apparatus, ${ }^{\mathrm{b}}$ isolated yields, average of two separate reactions; ${ }^{\mathrm{c}}$ argon was bubbled in the reaction mixture before the addition of the base. 
Using microwave heating at $100^{\circ} \mathrm{C}$ for $1 \mathrm{~h}$ in DMF (0.5M) with 2.0 equivalents of $t$-BuOLi gave a mixture of 2,5-dihydro-1H-imidazole 6ac (23\%), imidazole 7ac (16\%) and 4,5-dihydro-1H-imidazole 8 ac $(12 \%)$ that incorporates two ketenimine fragments (entry 1$)$. When the concentration was increased from $0.2 \mathrm{M}$ to $0.5 \mathrm{M}$, a mixture was still obtained but the overall yield improved by $13 \%$ (entry 2 ). Other solvents were tested (see Supplementary Information for fully detailed optimization) but were found to be totally ineffective (THF, entry 3 ) or did not bring any improvement (DMA, entry 4). Presence of the base was found to be essential (entry 5) but alternative inorganic $\left(\mathrm{Cs}_{2} \mathrm{CO}_{3}\right.$, entry 6 ) or organic (DBU, entry 7 ) bases did not promote the reaction. The formation of the oxidized derivative 7ac could be almost entirely suppressed by bubbling argon in the reaction mixture (entries 8-13). Various Lewis acid-type additives were screened (entries $8-10), Z n(I I)$ salts giving the best results (entries $8 \& 10$ ). The hygroscopic nature of these salts (in particular zinc triflate) led us to increase the number of equivalents of base to compensate for the induced hydrolysis (entries 10). Lowering the temperature to $80^{\circ} \mathrm{C}$ did not overly affect the yield (entry 11). Finally, to reduce the formation of $8 \mathrm{ac}$, the ynamide to imine ratio was diminished (entry $12 \& 13$ ) and better and more consistent results were obtained with a larger excess of base (4.4 equivalents, entry 13). These conditions gave the desired adduct 6ac in $62 \%$ yield, mostly avoiding the formation of side-products $7 \mathrm{ac}$ and $8 \mathrm{ac}$ and were selected to explore the scope of this [3+2] annulation.

First, benzylic aldimines 3 leading to symmetrical azaallyl anions 5 , having various groups $-\mathrm{H}$ $(\mathbf{3 d})$, halogens $(\mathbf{3 e}, \mathbf{f}, \mathbf{h}), \mathrm{MeO}(\mathbf{3 g})$ and electron withdrawing groups $(\mathbf{3 i}, \mathbf{j})$ on the para positions, were screened. The 1,5-dihydro- $1 \mathrm{H}$-imidazoles 6 were obtained in moderate to good yields with good to excellent diastereoselectivities in favor of the cis-isomer (Scheme 2a), as confirmed by single-crystal X-ray diffraction analysis for $\mathbf{6 a g}$ (Scheme $2 b$ ). The reaction was not operative for imines bearing strong electron withdrawing groups such as CF3 or NO2 $(\mathbf{3 i}, \mathbf{j})$, and the low solubility of diiodo imine $3 \mathrm{~h}$ was detrimental to the reaction's success. Nevertheless, imines bearing heterocycles such as 2-furanyl (3k), 2-thiophenyl (3i) or 2-pyridinyl (3m) were well tolerated. Finally, the 1,1-diphenyl-ketimine $\mathbf{3 n}$ was also subjected to the reaction conditions, forming 6 al as a single regioisomer in $72 \%$ yield. This is in sharp contrast to the reactivity of aldimines bearing two different aryl groups, such as $\mathbf{3 b}$ (see Scheme 1), that leads to inseparable mixtures of regioisomers. The scope of the ynamide partner was then delineated (Scheme 2c). As with the imino-Staudinger [2+2] cycloaddition, ${ }^{9}$ only ynamides bearing an aryl group on the nitrogen were suitable for the generation of the ketenimine intermediate and Boc was the best leaving group. N-Aryl ynamides bearing halogens $(\mathrm{Cl}$ and $\mathrm{Br}, \mathbf{1} \mathbf{b}, \mathbf{c})$, electron-donating (OMe and OEt, 
1e,f) or electron withdrawing (CF3, 19) groups gave 1,5-dihydro-1H-imidazoles 6 as the major adducts, generally along with minor amounts of double addition compound $\mathbf{8}$. Again, the low solubility of the $\mathrm{p}$-iodo compound was responsible for the low yield of $6 \mathbf{d c}$, while the p-nitro functionality (1 $\mathbf{h})$ was incompatible with the reaction conditions. The reaction was also succesful if the triple bond was substituted by an alkyl (n-Bu, 6ic), an aryl (Ph, 6jc) or a silyl (TIPS, 6kc), albeit with a low $18 \%$ yield in this case.

\section{Scheme 2. Scope of the $[3+2]$ annulation}

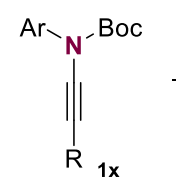

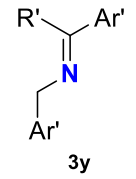<smiles>CCCCCC(C)(C)C</smiles>

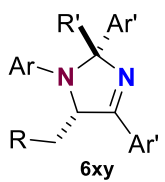

$6 x y$

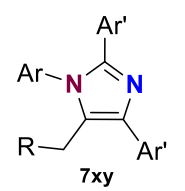

$7 x y$

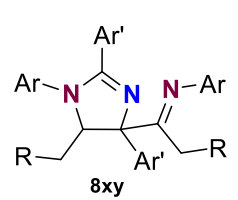

$8 x y$ conditions: namide 1 (1.5 equiv.) imine 3 , (1.0 equiv.) $\mathrm{Zn}(\mathrm{OAc})_{2} \cdot 2 \mathrm{H}_{2} \mathrm{O}(10 \mathrm{~mol} \%)$ DMF [0.2 M] t-BuOLi 4.4 equiv $80^{\circ} \mathrm{C}, 1 \mathrm{~h}$

a. scope: variation of the imine
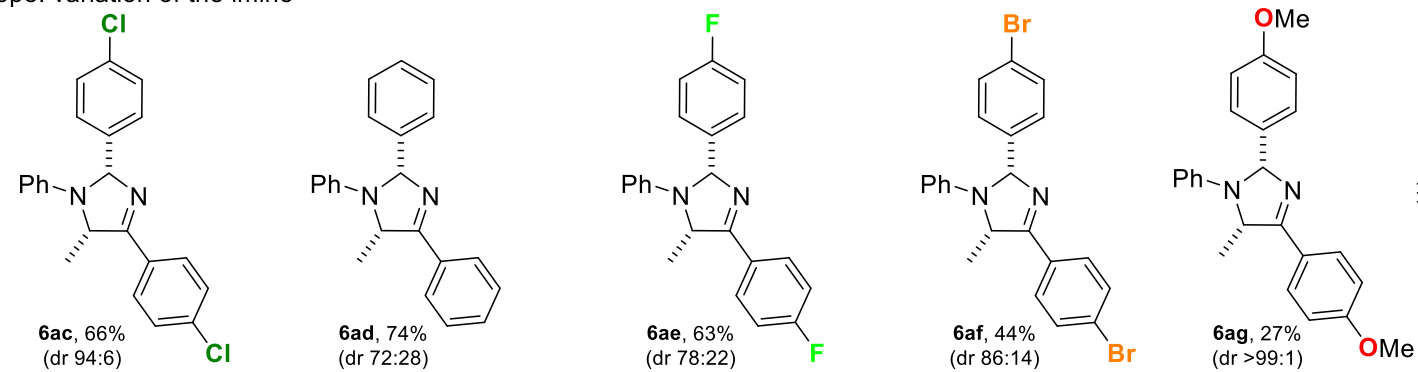

b. X-ray structure of 6 ag
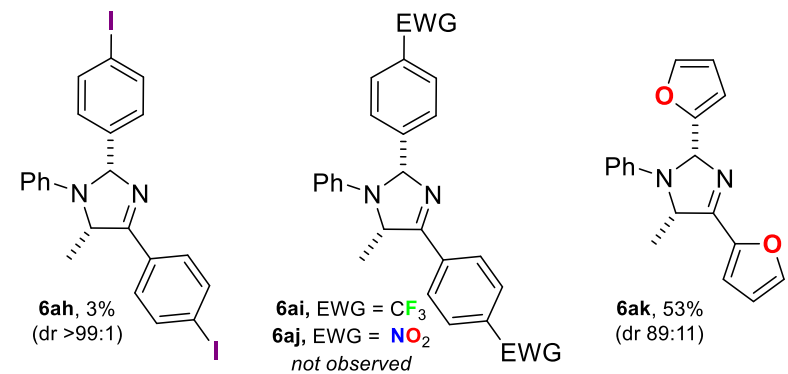

(dr 89:11)

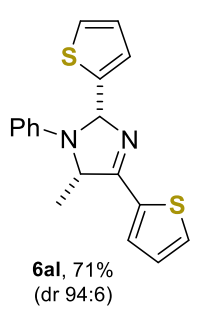

c. scope: variation of the ynamide
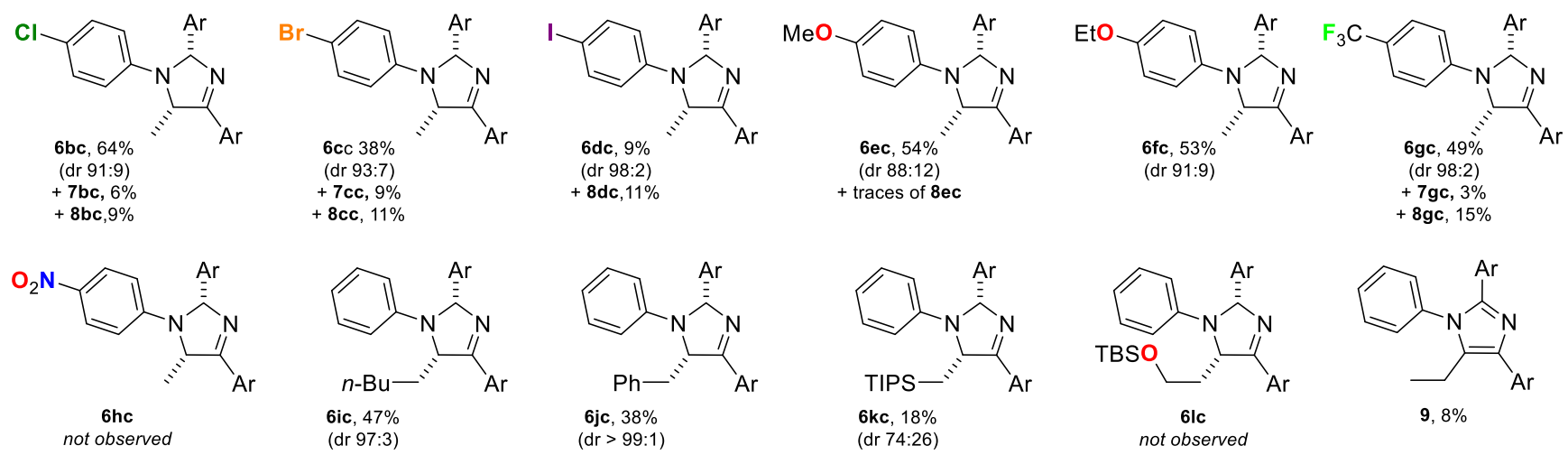

$6 a g$
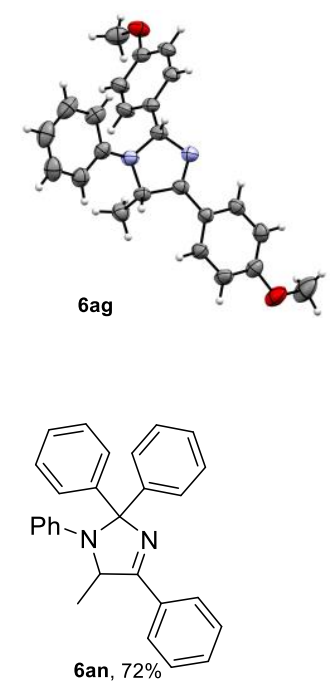

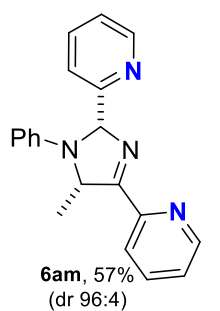
not observed $(\mathrm{dr}>99: 1)$

(dr 74:26)

not observe 
When an ynamide bearing a silyl-protected hydroxymethyl group on the triple bond (1I) was submitted to the reaction conditions, instead of the expected 6lc imidazole 9 was isolated. The latter would not come from an oxidation process as for imidazole $\mathbf{8}$. Instead, it would rather result from a [3+2] annulation with a cumulenimine (see 2l', Scheme 4c) to give a vinylated 1,5-dihydro- $1 \mathrm{H}$-imidazole, followed by the isomerization of the double bond.

In order to gain more insight on the [3+2] annulation process and the formation of side products 7 and $\mathbf{8}$, we performed several control experiments. First, deuterated ynamide 1a-D was synthesized and reacted with imine 3c (Scheme 3a). All adducts 6ac, 7ac and 8ac were isolated as mixtures of non- and mono-deuterated compounds, predominantly corresponding to the initial ynamide deuterium position ( $\mathrm{C} 1$ as well as $\mathrm{C} 4$ for $\mathbf{8 a c}$ ). For $6 \mathrm{ac}-\mathrm{D}$ other deuterium incorporation sites were identified at the $\mathrm{C} 2$ and $\mathrm{C} 3$ positions of the five-membered ring. A complementary experiment was performed by reacting ynamide 1a with the bis-deuterated imine 3c-D2 (Scheme $3 b$ ). In this setting, the adducts were obtained as non-, mono- and di-deuterated compounds, again with several deuterium incorporation sites at C1, C2, C3 and/or C4, including a double deuteration at C4 for 8ac-D2. This broad distribution pattern seems to indicate that many proton exchange steps take place during the formation of the five-membered adducts. However no deuteration was observed when the reaction was performed in deuterated DMF. To ascertain whether some elemental steps in our manifold are reversible, we resubmitted cis-6ac to the reaction conditions with 1.5 equivalents of $1 \mathrm{a}$ (Scheme $3 \mathrm{c}$ ).

\section{Scheme 3. Control experiments}

a. reaction with deuterated ynamide $1 \mathrm{a}-\mathrm{D}$
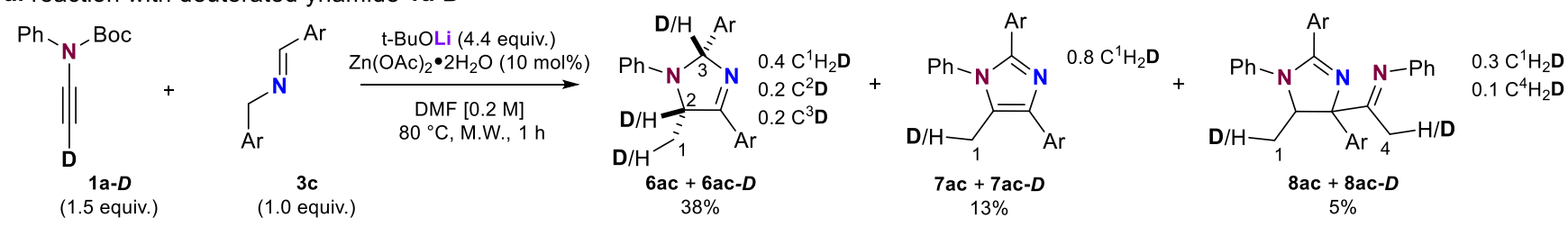

b. reaction with deuterated imine $3 c-D_{2}$
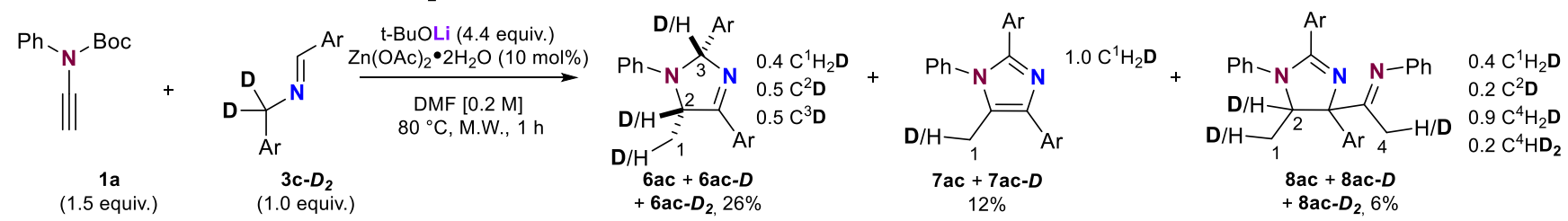

c. reaction between ynamide $1 \mathrm{a}$ and cis adduct cis-6ac
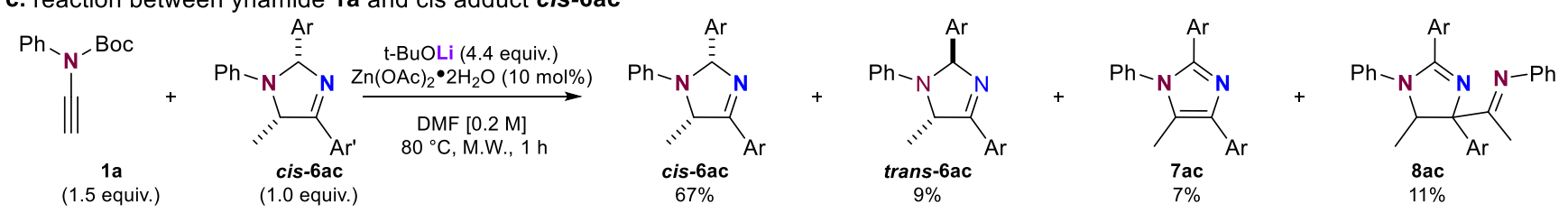
While cis-6ac was mostly recovered (67\% yield), the trans isomer (trans-6ac, $9 \%$ ), the imidazole resulting from an oxidation (7ac, 7\%) and the double addition adduct (8ac, 11\%) were also obtained. Interestingly, 8ac did not give back 6ac when it was subjected to the same reaction conditions (minus the ynamide). Finally, heating a DMF solution of 6 ac at $80^{\circ} \mathrm{C}$ for $1 \mathrm{~h}$ after bubbling air for 10 min only marginally led to the formation of $7 \mathrm{ac}(<5 \%)$.

Considering all these results a plausible mechanistic proposal was outlined and validated using DFT calculations (Scheme 4a). Under the strongly basic conditions, and possibly with the assistance of the zinc Lewis acid, ${ }^{46}$ partial decomposition of the DMF to give lithium dimethylamide would be the trigger to initiate the cleavage of the Boc protecting group of ynamide 1 giving the semi-stabilized amide 10 that protonates to give ketenimine 2. The generation of dimethylamine in the reaction mixture was confirmed by the isolation of amidines $15,15-D_{6}$ (when DMF- $D_{7}$ was used) and 16 (Scheme $4 \mathrm{~b}$ ). The latter appears to be consistent with the formation of cumulenimine 2l', rather than the expected ketenimine 2l (Scheme 4c), from amide $10 \mathrm{I}$. Thus, its reaction with imine $3 \mathrm{c}$ would give a vinyl-1,5-dihydro- $1 \mathrm{H}$-imidazole, which isomerization would lead to ethylimidazole 9 (Scheme 2c).

Deprotonation of the imine $\mathbf{3}$ would give the semi-stabilized diaryl azaallyl anion $\mathbf{5}$ that can add onto the ketenimine to give enamide 11 , followed by cyclization to yield imidazolinide 12 . Overall this process is nearly energoneutral $\left(\Delta G=1.6 \mathrm{kcal} \mathrm{mol}^{-1}\right)$, the first step being exergonic by $14.8 \mathrm{kcal}^{\mathrm{mol}}{ }^{-1}$, with a rather low activation barrier (3.1 kcal. mol$\left.{ }^{-1}\right)$ (Figure S1). From this intermediate, successive protonations and deprotonations as well as tautomerization of the enamide and/or imine moieties can take place explaining the complex deuteration patterns that we observed (Scheme 3a \& 3b). These experiments also indicate that the imine is the major purveyor of protons and that the ynamide only contributes to a lesser extent; the protons being channeled either by direct deprotonation or through the tert-butanol generated from an initial deprotonation with the lithium tert-butoxide. By modelling the various anions resulting from these events (Figure S2) we were able to identify azaallyl anion 13 as being the most favored at -28.1 $\mathrm{kcal}$.mol ${ }^{-1}$. A final reversible (as evidenced by the experiment in Scheme 3c) protonation would give 6. Alternatively, its reaction with another equivalent of ketenimine would lead to 8. Calculations indicated that addition at the benzylamine position, rather than at the aminal position, of 13 to give anion 14, leading to the observed regioisomer $\mathbf{8}$, was indeed favored thermodynamically by $5.6 \mathrm{kcal}^{\mathrm{mol}}{ }^{-1}$ (Figure S3). Although the stereochemistry of $\mathbf{8}$ could not be unambiguously ascertained, the cis stereoisomer would be obtained as the activation barrier would only be $3.214 .8 \mathrm{kcal}_{\mathrm{mol}}^{-1} \mathrm{vs} .8 .414 .8 \mathrm{kcal}_{\mathrm{mol}}{ }^{-1}$ for the trans isomer (Figure S3). Moreover, in the presence of dioxygen in the reaction medium, 13 it could be oxidized to 7 , presumably through an intermediate peroxide anion that would readily aromatize. 


\section{Scheme 4. Proposed mechanism}

a. proposed mechanism
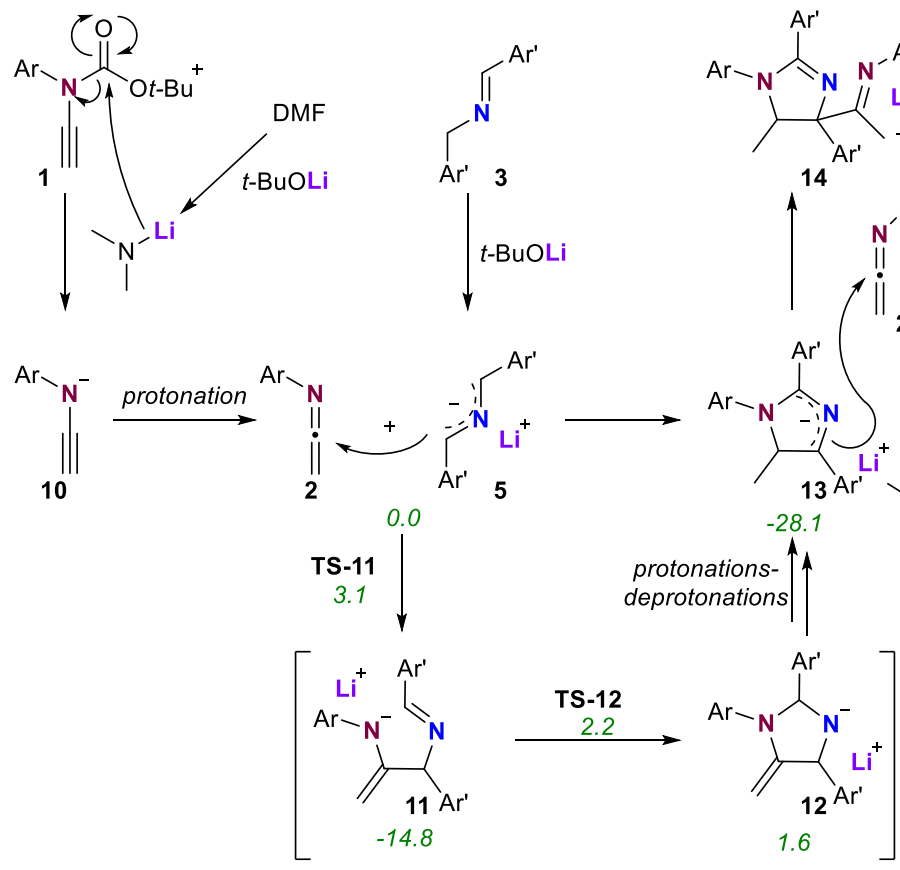

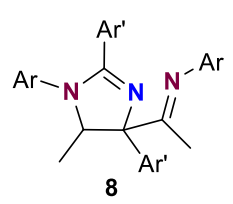

14

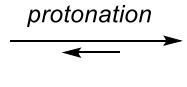

$$
\text { Ar }
$$

b. isolated side products

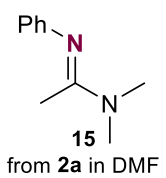

$\mathrm{Ph}_{\mathrm{N}_{\mathrm{N}} \mathrm{H}}$

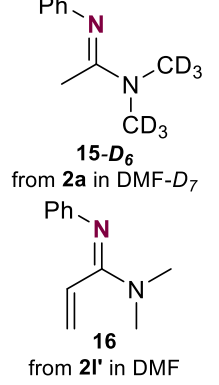

c. cumulenimine intermediate

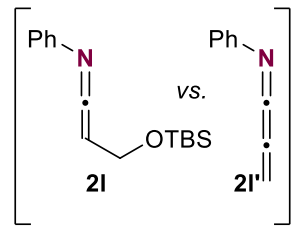

To conclude we have been able to develop a novel [3+2] annulation between ketenimines and azaallyl anions (both generated in situ from ynamides and benzylarylimines, respectively) to access five-membered heterocycles. The reaction mechanism was elucidated by using a combination of control experiments and DFT calculations, which seem to exclude a concerted process. Taken together our results open new synthetic opportunities towards nitrogen-containing heterocycles and evaluation of these as therapeutically relevant compounds is currently underway in our laboratory.

\section{ASSOCIATED CONTENT}

The Supporting Information contains:

Experimental procedures, characterization data, and NMR spectra for all products (PDF)

Computed energies and Cartesian coordinates of all the DFT-optimized structures (TXT)

X-ray crystallographic data for 6ag (CCDC 2032327) (CIF)

X-ray crystallographic data for 7ac (CCDC 2032327) (CIF)

\section{AUTHOR INFORMATION}

\section{Corresponding Author}

* Kevin Cariou kevin.cariou@cnrs.fr 


\section{Author Contributions}

This study was conceived by K. Cariou \& R. H. Dodd. Synthesis and characterization of the compounds were performed by A. C. A. D'Hollander, E. Romero, K. Vijayakumar and C. Le Houérou. X-ray crystallography was performed by P. Retailleau. Computational studies were performed by B. I. lorga. K. Cariou drafted the manuscript which was amended and commented on by all authors.

\section{Notes}

The authors declare no competing financial interest

\section{ACKNOWLEDGMENT}

This work was supported by the Laboratory of Excellence in Research on Medication and Innovative Therapeutics (LERMIT, grant ANR-10-LABX-33 under the program Investissements d'Avenir ANR-11IDEX-0003-01) and the SATT Paris-Saclay (project CARBAMAT). The authors also thank CNRS, Université Paris-Saclay, and ICSN, for financial support.

\section{REFERENCES}

(1) Staudinger, H. Zur Kenntniss Der Ketene. Diphenylketen. Justus Liebigs Ann. Chem. 1907, 356, 51-123.

(2) Pitts, C. R.; Lectka, T. Chemical Synthesis of $\beta$-Lactams: Asymmetric Catalysis and Other Recent Advances. Chem. Rev. 2014, 114, 7930-7953.

(3) Evano, G.; Coste, A.; Jouvin, K. Ynamides: Versatile Tools in Organic Synthesis. Angew. Chem. Int. Ed. 2010, 49, 2840-2859.

(4) DeKorver, K. A.; Li, H.; Lohse, A. G.; Hayashi, R.; Lu, Z.; Zhang, Y.; Hsung, R. P. Ynamides: A Modern Functional Group for the New Millennium. Chem. Rev. 2010, 110, 5064-5106.

(5) Wang, X.-N.; Yeom, H.-S.; Fang, L.-C.; He, S.; Ma, Z.-X.; Kedrowski, B. L.; Hsung, R. P. Ynamides in Ring Forming Transformations. Acc. Chem. Res. 2014, 47, 560-578.

(6) Hentz, A.; Retailleau, P.; Gandon, V.; Cariou, K.; Dodd, R. H. Transition-Metal-Free Tunable Chemoselective N Functionalization of Indoles with Ynamides. Angew. Chem. Int. Ed. 2014, 53, 8333-8337.

(7) Lu, P.; Wang, Y. The Thriving Chemistry of Ketenimines. Chem. Soc. Rev. 2012, 41, 5687-5705.

(8) Dodd, R. H.; Cariou, K. Ketenimines Generated from Ynamides: Versatile Building Blocks for Nitrogen-Containing Scaffolds. Chem. - Eur. J. 2017.

(9) Romero, E.; Minard, C.; Benchekroun, M.; Ventre, S.; Retailleau, P.; Dodd, R. H.; Cariou, K. Base-Mediated Generation of Ketenimines from Ynamides: Direct Access to Azetidinimines by an Imino-Staudinger Synthesis. Chem. - Eur. J. 2017, 23, 12991-12994.

(10) Eugénie Romero; Saoussen Oueslati; Mohamed Benchekroun; Agathe C. A. D'Hollander; Sandrine Ventre; Kamsana Vijayakumar; Corinne Minard; Cynthia Exilie; Linda Tlili; Pascal Retailleau; et al. Azetidinimines as a Novel Series of Non-Covalent Broad-Spectrum Inhibitors of $\beta$-Lactamases with Submicromolar Activities Against Carbapenemases of Classes A, B and D. February 25, 2020.

(11) Li, M.; Gutierrez, O.; Berritt, S.; Pascual-Escudero, A.; Yeşilçimen, A.; Yang, X.; Adrio, J.; Huang, G.; Nakamaru-Ogiso, E.; Kozlowski, M. C.; et al. Transition-Metal-Free Chemo- and Regioselective Vinylation of Azaallyls. Nat. Chem. 2017, 9, 997-1004.

(12) Shelp, R. A.; Walsh, P. J. Synthesis of BCP Benzylamines From 2-Azaallyl Anions and [1.1.1]Propellane. Angew. Chem. Int. Ed. 2018, 57, 15857-15861.

(13) Namitharan, K.; Pitchumani, K. Copper(I)-Catalyzed Three Component Reaction of Sulfonyl Azide, Alkyne, and Nitrone Cycloaddition/Rearrangement Cascades: A Novel One-Step Synthesis of Imidazolidin-4-Ones. Org. Lett. 2011, 13, 5728-5731.

(14) Li, S.; Luo, Y.; Wu, J. Three-Component Reaction of N'-(2-Alkynylbenzylidene)Hydrazide, Alkyne, with Sulfonyl Azide via a Multicatalytic Process: A Novel and Concise Approach to 2-Amino-H-Pyrazolo[5,1-a]lsoquinolines. Org. Lett. 2011, 13, 4312-4315.

(15) Alajarin, M.; Bonillo, B.; Ortin, M.-M.; Orenes, R.-A.; Vidal, A. Unprecedented Intramolecular [3 + 2] Cycloadditions of Azido-Ketenimines and Azido-Carbodiimides. Synthesis of Indolo[1,2-a]Quinazolines and Tetrazolo[5,1-b]Quinazolines. Org. Biomol. Chem. 2011, 9, 6741-6749. 
(16) Kauffmann, T.; Berg, H.; Ludorff, E.; Woltermann, A. Anionic $3+2$ Cycloaddition of 2-Azaallyllithium Compounds to CN and NN Double Bonds. Angew. Chem. Int. Ed. Engl. 1970, 9, 960-961.

(17) Kauffmann, T.; Berg, H.; Köppelmann, E. Anionic $3+2$ Cycloaddition. Angew. Chem. Int. Ed. Engl. 1970, 9, 380-381.

(18) Pearson, W. H.; Stoy, P. Cycloadditions of Nonstabilized 2-Azaallyllithiums (2-Azaallyl Anions) and Azomethine Ylides with Alkenes: [3+2] Approaches to Pyrrolidines and Application to Alkaloid Total Synthesis. Synlett 2003, 2003, 0903-0921.

(19) Otero-Fraga, J.; Montesinos-Magraner, M.; Mendoza, A. Perspectives on Intermolecular Azomethine Ylide [3+2] Cycloadditions with Non-Electrophilic Olefins. Synthesis 2017, 49, 802-809.

(20) Otero-Fraga, J.; Suárez-Pantiga, S.; Montesinos-Magraner, M.; Rhein, D.; Mendoza, A. Direct and Stereospecific [3+2] Synthesis of Pyrrolidines from Simple Unactivated Alkenes. Angew. Chem. Int. Ed. 2017, 56, 12962-12966. 
GRAPHICAL ABSTRACT

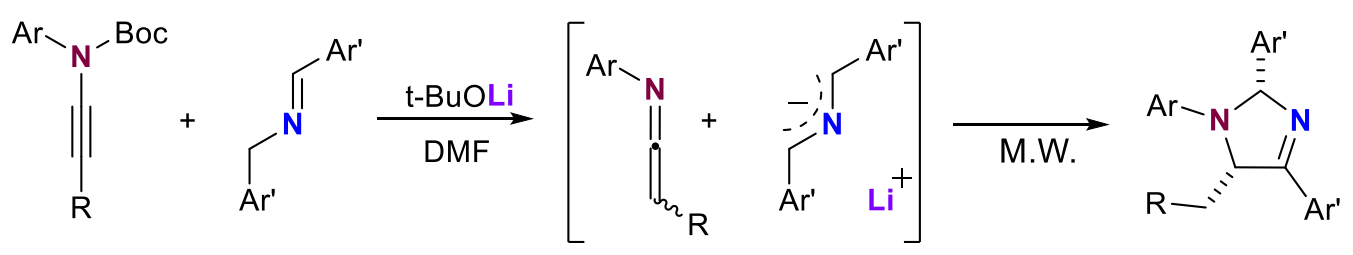

